BASTIANI, Ana Cristina Bacega de; SANTOS, Daniela dos. A condição humana e o respeito à dignidade na proteção do direito ao meio ambiente saudável previsto pelo artigo 225 da Constituição Federal. Revista Eletrônica Direito e Política, Programa de Pós-Graduação Stricto Sensu em Ciência Jurídica da UNIVALI, Itajaí, v.10, n.1, edição especial de 2015. Disponível em: www.univali.br/direitoepolitica - ISSN 1980-7791.

\title{
A CONDIÇÃO HUMANA E O RESPEITO À DIGNIDADE NA PROTEÇÃO DO DIREITO AO MEIO AMBIENTE SAUDÁVEL PREVISTO PELO ARTIGO 225 DA CONSTITUIÇÃO FEDERAL
}

\author{
THE HUMAN CONDITION AND RESPECT THE DIGNITY TO PROTECT THE \\ RIGHT TO HEALTHY ENVIRONMENT PROVIDED BY ARTICLE 225 OF THE \\ FEDERAL CONSTITUTION
}

\author{
Ana Cristina Bacega De Bastiani ${ }^{1}$ \\ Daniela dos Santos ${ }^{2}$
}

SUMÁRIO: Introdução; 1. A Condição Humana como Valor Base à Dignidade da Pessoa Humana; 2. Delimitações Teóricas dos Direitos Fundamentais; 30 direito fundamental a um meio ambiente equilibrado essencial à sadia qualidade de vida; Considerações Finais; Referências das Fontes Citadas.

RESUMO: O trabalho analisa a condição humana segundo Hannah Arendt, com um enfoque no processo de evolução do homem, sendo ele agente transformador da realidade. Em um Estado Democrático de Direito é preciso promover políticas de desenvolvimento econômico sustentável, e cabe ao homem conscientizar-se de que suas ações individuais fazem toda a diferença na preservação do meio em que vive. Portanto o direito a um meio ambiente equilibrado, essencial à sadia qualidade de vida, unifica toda a pesquisa, já que do comportamento do homem dependem as boas condições ambientais para sua própria sobrevivência e seu bem estar. O objetivo é estudar os direitos fundamentais no Estado Democrático Brasileiro, considerando a importância da evolução na proteção dos direitos, diante de cada momento histórico, bem como demonstrar que, atualmente, faz-se necessário um olhar especial ao meio

\footnotetext{
1 Mestranda em Direito, Democracia e Sustentabilidade pela IMED - Faculdade Meridional. Especialista em Direito Processual Civil pela Faculdade Anhanguera de Passo Fundo e advogada. Passo Fundo - RS - Brasil. E-mail: cristi.bd@hotmail.com

2 Mestranda em Direito, Democracia e Sustentabilidade pela IMED - Faculdade Meridional. Especialista em Direito Civil e Direito Processual Civil pela Universidade Regional IntegradaErechim, Professora da Universidade de Passo Fundo. Passo Fundo - RS - Brasil. E-mail: danielasantos@upf.br.
} 
BASTIANI, Ana Cristina Bacega de; SANTOS, Daniela dos. A condição humana e o respeito à dignidade na proteção do direito ao meio ambiente saudável previsto pelo artigo 225 da Constituição Federal. Revista Eletrônica Direito e Política, Programa de Pós-Graduação Stricto Sensu em Ciência Jurídica da UNIVALI, Itajaí, v.10, n.1, edição especial de 2015. Disponível em: www.univali.br/direitoepolitica - ISSN 1980-7791.

ambiente, protegido expressamente pela Constituição Federal em seu artigo 225. Para tanto, utilizar-se-á o método dedutivo e a técnica de pesquisa bibliográfica.

Palavras-chave: Dignidade; Equilíbrio; Evolução; Sustentabilidade.

ABSTRACT: The study analyses the human condition, according to Hannah Arendt, focusing on the process of human evolution, considering human being as a subject who changes reality. In a Democratic Rule-of-Law State, promoting policies of sustainable economic development is needed, and it is up to human being to be aware of all the difference his individual actions make in preservating the environment where he lives. Therefore, the right to a well-balanced environment, that is essential to a healthy quality of life, unifies the whole research, once maintenence of good environmental conditions depends on human behavior, for his own survival and well-being. The scope is to study the fundamental rights in Brazilian Democratic State, considering the importance of growth of protection of rights, in the face of every historic moment as well as to demonstrate that currentlly it is necessary to have a special look at environment, which is absolutely protected by Federal Constitution, in its clause numbered 225. For this purpose, deductive method and bibliographic research technique will be used.

Keywords: Dignity; Balance; Evolution; Sustainability.

\section{INTRODUÇÃo}

O presente trabalho analisa a Condição Humana e o respeito à dignidade humana na efetivação de uma proteção a um direito ao meio ambiente saudável para uma sadia qualidade de vida diante dos ditames constitucionais do Estado Democrático de Direito vivenciado no Brasil na atualidade.

O respeito à dignidade da pessoa é analisado especialmente a partir do artigo 225 da Constituição Federal, que prevê em seu texto o direito a sustentabilidade, que promove qualidade de vida a partir da proteção do meio ambiente. "A Condição Humana" expressa nos ensinamentos de Hannah Arendt serve como base ao estudo, já que existe como uma máxima ao princípio da dignidade humana que se satisfaz quando condições de vida digna se concretizam para o homem. 
BASTIANI, Ana Cristina Bacega de; SANTOS, Daniela dos. A condição humana e o respeito à dignidade na proteção do direito ao meio ambiente saudável previsto pelo artigo 225 da Constituição Federal. Revista Eletrônica Direito e Política, Programa de Pós-Graduação Stricto Sensu em Ciência Jurídica da UNIVALI, Itajaí, v.10, n.1, edição especial de 2015. Disponível em: www.univali.br/direitoepolitica - ISSN 1980-7791.

Para que o Estado Democrático de Direito possa ser permanentemente construído, neste estudo é mister analisar o respeito das ações humanas no sentido da consciência de suas ações reflexivas. O ser humano deve estar atento à sua participação, que é fundamental no processo de construção do modelo de Estado que se vivencia, e que se quer cada dia mais consolidado. Analisando os direitos fundamentais de uma maneira geral, em específico o direito a sustentabilidade, voltado à análise da participação humana neste desenvolvimento, os objetivos da presente pesquisa são: demonstrar os desafios jurídicos e sociais para a concretização deste direito fundamental que hoje se encontra em construção; estudar os direitos fundamentais no Estado Democrático Brasileiro, considerando a importância da evolução na proteção dos direitos, diante de cada momento histórico; e evidenciar que, atualmente, é necessário um olhar especial ao meio ambiente, protegido expressamente pela Constituição Federal em seu artigo 225.

Assim, o problema a ser resolvido é: a sustentabilidade, como novo paradigma, carece da consciência humana para a sua construção? Parte-se do princípio de que, as ações humanas implicam diretamente para a promoção da sustentabilidade que se quer construir, a partir da previsão do artigo constitucional supracitado.

O direito a Sustentabilidade é proclamado, mas necessita de maturação, já que a previsão é a respeito da proteção ao meio ambiente equilibrado para que ocorra a sadia qualidade de vida. Portanto, este processo de evolução humana, que visa melhores condições de vida precisa ser desenvolvido no sentido da sustentabilidade ambiental e também humana.

Num primeiro momento, a pesquisa se destina ao estudo específico da Condição Humana, do desenvolvimento humano e sua influência para que o princípio da dignidade humana seja protegido de maneira real. Posteriormente, delimitam-se os direitos fundamentais de uma maneira geral, para, em um terceiro momento dar ênfase ao direito a um meio ambiente equilibrado voltado à promoção da qualidade de vida, analisando um possível direito à sustentabilidade no Estado Democrático de Direito, em que as ações humanas são o cerne para a construção 
BASTIANI, Ana Cristina Bacega de; SANTOS, Daniela dos. A condição humana e o respeito à dignidade na proteção do direito ao meio ambiente saudável previsto pelo artigo 225 da Constituição Federal. Revista Eletrônica Direito e Política, Programa de Pós-Graduação Stricto Sensu em Ciência Jurídica da UNIVALI, Itajaí, v.10, n.1, edição especial de 2015. Disponível em: www.univali.br/direitoepolitica - ISSN 1980-7791.

de um meio ambiente melhor para se viver. É um ambiente democrático, que exige a participação humana para a transformação da realidade e busca pela preservação de um ambiente adequado para a perpetuação da vida humana no planeta. Para tanto, utilizar-se-á o método dedutivo e a técnica de pesquisa bibliográfica.

\section{A CONDIÇÃo HUMANA COMO VALOR BASE À DIGNIDADE DA PESSOA HUMANA}

As teorias elaboradas por Hannah Arendt $^{3}$ contribuíram muito ao mundo contemporâneo, pois refletiram sobre o homem e sua colocação no mundo social em que vive. O homem é um ator social, mas houve uma evolução histórica de sua convivência para que se chegasse a tal estado, haja vista que nem sempre o homem conviveu da maneira como hoje.

A Condição Humana é neste estudo um ponto de partida, pois no processo civilizatório, são as suas ações que vão conduzir o futuro do Planeta. Influenciando diretamente este processo, cabe a ele agir com consciência diante desta realidade.

Arendt ${ }^{4}$ explica que "a condição humana compreende algo mais que as condições nas quais a vida foi dada ao homem. Os homens são seres condicionados: tudo aquilo com o qual eles entram em contato torna-se imediatamente uma condição de sua existência".

A autora pensou a respeito do homem enquanto ser e quais as qualidades que $o$ igualam e o diferenciam de outros seres vivos. Destacam-se explicações sobre o papel do homem em relação ao mundo e a si próprio, estudo este relevante para que se entenda que as ações do homem são determinantes para sua

\footnotetext{
${ }^{3}$ ARENDT, Hannah. A condição humana. Trad. Roberto Raposo. 10. ed. Rio de Janeiro: Forense Universitária, 2007.

${ }^{4}$ ARENDT, Hannah. A condição humana. p.17.
} 
BASTIANI, Ana Cristina Bacega de; SANTOS, Daniela dos. A condição humana e o respeito à dignidade na proteção do direito ao meio ambiente saudável previsto pelo artigo 225 da Constituição Federal. Revista Eletrônica Direito e Política, Programa de Pós-Graduação Stricto Sensu em Ciência Jurídica da UNIVALI, Itajaí, v.10, n.1, edição especial de 2015. Disponível em: www.univali.br/direitoepolitica - ISSN 1980-7791.

sobrevivência, da espécie humana, da sociedade e para a promoção de seus direitos e a afirmação da Democracia.

Em "A condição humana", Hannah Arendt reflete sobre aquilo que o homem está fazendo no mundo, explicando, assim, as três atividades que correspondem às condições básicas da vida humana, quais sejam: trabalho, labor e ação. Estas condições são elementos importantes para estudar a evolução do homem bem como a proteção de seus direitos que visam proteger o homem e sua dignidade.

A consagração da dignidade da pessoa humana considera o homem como o centro do universo jurídico, sendo que a pessoa humana é o fim de si mesma. Isto se justifica na medida em que a dignidade é decorrente de o ser humano ser respeitado enquanto tal, ou seja, a dignidade é algo que pertence ao ser humano em si, mas sem condições de vida adequadas ela não se realiza perfeitamente. Nesse interim, Sarlet ${ }^{5}$ conceitua dignidade da pessoa humana como

[...] uma qualidade intrínseca e distintiva de cada ser humano que o faz merecedor do mesmo respeito e consideração por parte do Estado e da comunidade, implicando, neste sentido, um complexo de direitos e deveres fundamentais que assegurem a pessoa tanto contra todo e qualquer ato de cunho degradante e desumano, como venham a lhe garantir as condições existentes mínimas para uma vida saudável, além de propiciar e promover sua participação ativa e co-responsável nos destinos da própria existência e da vida em comunhão com os demais seres humanos.

Para Kant ${ }^{6}$, o que caracteriza o ser humano e o faz dotado de dignidade especial é o fato de nunca poder servir de meio para outro ser humano. As pessoas não existem em função das outras e não podem servir como objeto, pois a pessoa humana encontra sentido em si mesma. O princípio da dignidade humana, como

5 SARLET, Ingo Wolfgang. Dignidade da pessoa humana e direitos fundamentais na Constituição Federal de 1988. 5. ed. Porto Alegre: Livraria do Advogado Ed., 2007. p. 62.

${ }^{6}$ KANT, Immanuel. Fundamentação da metafísica dos costumes. Trad. Paulo Quintela. Lisboa: Edições 70, 1995. 
BASTIANI, Ana Cristina Bacega de; SANTOS, Daniela dos. A condição humana e o respeito à dignidade na proteção do direito ao meio ambiente saudável previsto pelo artigo 225 da Constituição Federal. Revista Eletrônica Direito e Política, Programa de Pós-Graduação Stricto Sensu em Ciência Jurídica da UNIVALI, Itajaí, v.10, n.1, edição especial de 2015. Disponível em: www.univali.br/direitoepolitica - ISSN 1980-7791.

expressa Flávia Piovesan7, transcende os limites do positivismo, justamente por seu fundamento ser o próprio ser humano.

Com relação à dignidade no Brasil, esta hoje é protegida expressamente depois das histórias de lutas pelos direitos da pessoa humana. Com a promulgação da Constituição Federal de 1988, elaborada para ratificar a democracia, consolidouse o Estado Democrático de Direito $^{8}$. O texto constitucional trouxe estampados os direitos fundamentais, sendo um de seus fundamentos basilares a dignidade. É importante ressaltar que os princípios constitucionais são dotados de normatividade, gerando um direito subjetivo ao cidadão que pode exigir do Estado que os efeitos esperados dos princípios sejam concretizados.

O tema ora versado é de extrema relevância. Não há como entender e exigir direitos e princípios se não se chegar próximo, ao menos, do entendimento daquilo que o homem é, faz e da influência de sua condição. Só assim é possível entender o valor que a dignidade exerce sobre a existência humana, bem como a necessidade de proteção de seus direitos.

Sarlet ${ }^{9}$ explica que "em se levando em conta que a dignidade, acima de tudo, diz com a condição humana do ser humano, cuida-se de assunto de perene relevância e atualidade, tão perene e atual for a própria existência humana.".

Valendo-se do progresso humano no sentido de desenvolver novas técnicas de vida, que visam preservar não somente a espécie humana, mas uma vida melhor, o homem também deve continuar buscando a ratificação de seus direitos fundamentais que objetivam proteger aquilo de mais íntimo que existe no homem: sua dignidade.

\footnotetext{
7 PIOVESAN, Flávia. Temas de direitos humanos. São Paulo: Max Limonad, 2003.

8 "Destinado a assegurar o exercício dos direitos sociais e individuais, a liberdade, a segurança, o bem-estar, o desenvolvimento, a igualdade e a justiça como valores supremos de uma sociedade fraterna, pluralista e sem preconceitos, fundada na harmonia social e comprometida, na ordem interna e internacional, com a solução pacífica das controvérsias" (BRASIL, Constituição Federal, 1988). Nesse sentido, prevalece o princípio da soberania popular, ou seja, em um regime democrático, o soberano é o povo. Há uma harmonia entre o representante do poder soberano nas tarefas do governo com o poder decisório do povo. (COMPARATO, 2006, p. 86).
}

9 SARLET, Ingo Wolfgang. Dignidade da pessoa humana e direitos fundamentais na Constituição Federal de 1988. p. 27. 
BASTIANI, Ana Cristina Bacega de; SANTOS, Daniela dos. A condição humana e o respeito à dignidade na proteção do direito ao meio ambiente saudável previsto pelo artigo 225 da Constituição Federal. Revista Eletrônica Direito e Política, Programa de Pós-Graduação Stricto Sensu em Ciência Jurídica da UNIVALI, Itajaí, v.10, n.1, edição especial de 2015. Disponível em: www.univali.br/direitoepolitica - ISSN 1980-7791.

A dignidade, na condição de valor intrínseco do ser humano, gera para o indivíduo o direito de decidir de forma autônoma sobre seus projetos existenciais. Mesmo onde esta autonomia Ihe faltar, o princípio deve ser considerado e respeitado pela sua íntima relação com a condição humana, segundo Sarlet ${ }^{10}$. A condição humana é a base para que o princípio da dignidade da pessoa humana seja reconhecido. Esta e seus desdobramentos exercem um papel que dá unidade, sentido e coerência aos direitos fundamentais previstos no sistema jurídico.

Assim, protegida a condição humana como um valor base à dignidade do homem pode-se ter a certeza de que os outros direitos fundamentais pertencentes ao homem terão condições de serem ratificados, pois sem o devido respeito às condições intrínsecas ao homem, não há princípio e nem direito que seja confirmado no plano real. Como explica Figueiredo ${ }^{11}$

[...] a dignidade da pessoa humana, ademais, é pré-jurídica, não existindo apenas quando e na medida em que corroborada pelo Direito, já que possui um dado prévio, um conceito a priori. Portanto, não se cogita nem de pretensão jurídica, nem tampouco de direito fundamental à dignidade humana; o que há são pretensões jurídicas a direitos subjetivos decorrentes da dignidade da pessoa humana, ou ainda uma pretensão de respeito e proteção que dela pode decorrer. Não há direito fundamental à dignidade da pessoa humana - embora se possa pensar num direito à existência digna.

Pode o homem, assim, ter reconhecido algum direito, mas caso não tenha sido respeitada a sua dignidade, não há a sua efetivação. Logo, a condição humana é a base para o entendimento da evolução do homem e de seus direitos. É preciso respeitar a dignidade humana e os direitos que dela decorrem, para que o homem possa perceber que sua evolução enquanto homem e também enquanto sociedade surte resultados no sentido de buscar sempre um maior entendimento e proteção a respeito de sua condição e seus direitos.

\footnotetext{
10 SARLET, Ingo Wolfgang. Dignidade da pessoa humana e direitos fundamentais na Constituição Federal de 1988. p. 52.

11 FIGUEIREDO, Mariana Filchtiner. Direito fundamental à saúde: parâmetros para sua eficácia e efetividade. Porto Alegre: Livraria do Advogado Editora, 2007.p. 53.
} 
BASTIANI, Ana Cristina Bacega de; SANTOS, Daniela dos. A condição humana e o respeito à dignidade na proteção do direito ao meio ambiente saudável previsto pelo artigo 225 da Constituição Federal. Revista Eletrônica Direito e Política, Programa de Pós-Graduação Stricto Sensu em Ciência Jurídica da UNIVALI, Itajaí, v.10, n.1, edição especial de 2015. Disponível em: www.univali.br/direitoepolitica - ISSN 1980-7791.

O conjunto das características e atividades humanas faz com que o homem, a partir de sua razão e consciência, perceba que é um ser diferenciado dos demais e, portanto, merecedor de tratamento particular. Contudo, ele também possui deveres na busca pela ratificação de seus direitos, bem como de preservar o meio para que também as futuras gerações possam usufruí-los com qualidade.

\section{DELIMITAÇõES TEÓRICAS DOS DIREITOS FUNDAMENTAIS}

Para Bobbio $^{12}$, os direitos do homem, por mais fundamentais que sejam, são direitos nascidos em certas circunstâncias e tempo, caracterizados por lutas em defesa de novas liberdades contra velhos poderes, e gradualmente, não todos de uma vez e nem de uma vez por todas. Acrescenta o autor que "o problema fundamental em relação aos direitos do homem, hoje, não é tanto o de justificá-los, mas o de protegê-los trata-se de um problema não filosófico, mas político" ${ }^{13}$ (grifos nossos).

Dimoulis e Martins ${ }^{14}$ concordam e explicam que os direitos fundamentais também possuem esta aproximação com a política, os direitos fundamentais "foram impostos politicamente no meio de ferozes lutas, de revoluções, de guerras civis e de outros acontecimentos 'de ruptura'".

Em face da problemática acerca dos direitos do homem, pode-se afirmar que para sua realização é preciso vontade política. A atuação do Estado por meio de escolhas democráticas faz toda a diferença nas suas prioridades de realização de direitos, superando as barreiras a serem ultrapassadas pela sociedade na busca pela efetivação de seus direitos.

\footnotetext{
${ }^{12}$ BOBBIO, Norberto. A Era dos Direitos. Trad. Carlos Nelson Coutinho. 6. ed. Rio de Janeiro: Elsevier, 2004. p. 5.

${ }^{13}$ BOBBIO, Norberto. A Era dos Direitos. p. 23.

${ }^{14}$ DIMOULIS, Dimitri; MARTINS, Leonardo. Teoria geral dos direitos fundamentais. São Paulo: Editora Revista dos Tribunais, 2007. p.17
} 
BASTIANI, Ana Cristina Bacega de; SANTOS, Daniela dos. A condição humana e o respeito à dignidade na proteção do direito ao meio ambiente saudável previsto pelo artigo 225 da Constituição Federal. Revista Eletrônica Direito e Política, Programa de Pós-Graduação Stricto Sensu em Ciência Jurídica da UNIVALI, Itajaí, v.10, n.1, edição especial de 2015. Disponível em: www.univali.br/direitoepolitica - ISSN 1980-7791.

Para Steinmetz ${ }^{15}$, "os direitos fundamentais são direitos positivos, constitucionalizados". Entendido que várias são as definições encontradas para delimitar o que são os direitos fundamentais, ainda é preciso delimitar o âmbito de atuação destes direitos, haja vista que estes foram surgindo de modo gradual. Partindo-se dos direitos de limitação do poder, exigência do Estado ainda liberal/individualista, no nascedouro dos direitos fundamentais até os dias de hoje, de um Estado com uma efetiva interligação com o ente privado, houve uma trajetória percorrida por estes direitos, quando tiveram que superar à 'crença que teriam uma dimensão puramente axiológica, ética, sem eficácia jurídica ou aplicabilidade direta e imediata', a fim de conquistar o status de norma jurídica ${ }^{16}$.

Ocorre que os direitos fundamentais nem sempre tiveram esse status normativo. Esses direitos possuem uma caracterização subjetiva, tendo em vista serem dotados de valores implícitos. Os direitos fundamentais são resultado da vontade de positivar valores básicos e com isso acabam sendo à base da estrutura normativa do Estado. Sarlet ${ }^{17}$, nesta senda, explica que

Os direitos fundamentais, como resultado da personalização e positivação constitucional de determinados valores básicos (daí seu conteúdo axiológico), integram, ao lado dos princípios estruturais e organizacionais [...] a substância propriamente dita, o núcleo substancial, formado pelas decisões fundamentais, da ordem normativa.

Assim, em um Estado Democrático de Direito, a proteção aos direitos fundamentais é essencial. O conhecimento de seus direitos por parte dos cidadãos é de suma importância, pois conhecendo os direitos, eles tornam-se mais possíveis de efetivação, já que cada um saberá o que pode e como exigir.

15 STEINMETZ, Wilson Antonio. Colisão de direitos fundamentais e princípio da proporcionalidade. Porto Alegre: Livraria do Advogado, 2001.p. 19.

16 REIS, Jorge Renato dos. Os direitos fundamentais de tutela da pessoa humana nas relações entre particulares. In: REIS, Jorge Renato dos; LEAL, Rogério Gesta (Org). Direitos sociais \& políticas públicas: desafios contemporâneos. Santa Cruz do Sul: EDUNISC, 2007, p. 2033.

17 SARLET, Ingo Wolfgang. A eficácia dos direitos fundamentais: uma teoria geral dos direitos fundamentais na perspectiva constitucional. 10. ed. Porto Alegre: Livraria do Advogado, 2009. p. 61. 
BASTIANI, Ana Cristina Bacega de; SANTOS, Daniela dos. A condição humana e o respeito à dignidade na proteção do direito ao meio ambiente saudável previsto pelo artigo 225 da Constituição Federal. Revista Eletrônica Direito e Política, Programa de Pós-Graduação Stricto Sensu em Ciência Jurídica da UNIVALI, Itajaí, v.10, n.1, edição especial de 2015. Disponível em: www.univali.br/direitoepolitica - ISSN 1980-7791.

Como já considerado, os direitos fundamentais são frutos de processos históricos e lutas humanas para sua proteção. A história demonstra que conforme o tempo passa, e a sociedade vai se modificando, as propostas de proteção a direitos também vão se transformando. Guimarães ${ }^{18}$ a respeito dos direitos fundamentais, acrescenta que eles "compõe-se de um conjunto de direitos e garantias do ser humano que buscam a implementação do respeito a uma vida digna, sadia, com a perspectiva de desenvolvimento geral, com liberdade, solidariedade e igualdade".

De acordo com os ensinamentos de Guimarães ${ }^{19}$ e, conforme o que já fora dito sobre como os direitos surgem de maneira gradual e em conformidade com as transformações da realidade social, o que se pretende demonstrar com esse estudo, é que, embora a proteção dos direitos do homem seja o ponto chave para uma vida digna, o momento atual é de atenção aos direitos a um meio ambiente saudável.

\section{O DIREITO FUNDAMENTAL A UM MEIO AMBIENTE EQUILIBRADO ESSENCIAL À SADIA QUALIDADE DE VIDA}

O direito a um meio ambiente saudável está previsto na Constituição Federal de 1988 em seu artigo 225 caput $^{20}$, e é elevado a status de direito fundamental. Está, ainda, intimamente ligado à proteção de outros direitos fundamentais. O artigo citado demonstra que além dos direitos fundamentais do homem, é preciso também que um direito a um meio ambiente saudável seja perseguido,

18 GUIMARÃES, Bérgson Cardoso. Fundamentos ético-filosóficos para a preservação dos bens culturais. In: Revista Magister de Direito Ambiental e Urbanístico. Porto Alegre: Magister, 2013, p. 102.

19 GUIMARÃES, Bérgson Cardoso. Fundamentos ético-filosóficos para a preservação dos bens culturais. p. 102.

20 Art. 225 - "Todos têm direito ao meio ambiente ecologicamente equilibrado, bem de uso comum do povo e essencial à sadia qualidade de vida, impondo-se ao Poder Público e à coletividade o dever de defendê-lo e preserva-lo para as presentes e futuras gerações". (BRASIL, Constituição Federal, 1988). 
BASTIANI, Ana Cristina Bacega de; SANTOS, Daniela dos. A condição humana e o respeito à dignidade na proteção do direito ao meio ambiente saudável previsto pelo artigo 225 da Constituição Federal. Revista Eletrônica Direito e Política, Programa de Pós-Graduação Stricto Sensu em Ciência Jurídica da UNIVALI, Itajaí, v.10, n.1, edição especial de 2015. Disponível em: www.univali.br/direitoepolitica - ISSN 1980-7791.

já que a própria condição humana importa ao homem um desenvolvimento que preserve sua qualidade de vida. Guimarães ${ }^{21}$ explica que

[...] a ligação do homem com o meio ambiente, com seu meio natural guarda uma simbologia [...] que deve ser compreendida sob o enfoque da necessidade de se identificar a natureza antropológica e social do homem com seu espaço ecológico, indissociáveis.

Portanto, o homem deve atuar de forma a proteger e conservar os recursos naturais que viabilizam uma existência digna, já que para preservar sua própria vida, é necessária também a proteção ao meio em que vive e se desenvolve.

Para que o homem possa continuar seu processo de evolução é preciso o respeito ao meio ambiente para que tal desenvolvimento seja sustentável. Isso apenas ocorre a partir de ações sustentáveis e condições de vida saudáveis proporcionadas por estas condutas, pois isso é a condição humana e demonstra a importância do Estado Democrático de Direito, no sentido da garantia de direitos aliado a participação do homem neste processo de evolução. Demonstrase assim, que o homem está diretamente ligado neste processo de preservação do meio e construção de um direito fundamental à sustentabilidade que seja efetivamente respeitado.

Medeiros e Petterle 22 explicam que "à luz da temática ambiental, urge realizar a transferência da proteção ao ambiente do terreno dos direitos fundamentais para o âmbito dos deveres". E acrescentam que se trata de "uma necessidade de se ultrapassar a euforia dos direitos fundamentais sob a ótica do individualismo e de se alicerçar o conceito de uma comunidade responsável em face de problemas ambientais coletivos".

A influência entre o respeito a direitos fundamentais e o dever do homem no que tange a realidade ambiental, demonstra ser uma nova maneira de encarar os problemas ambientais, causados pelo próprio homem. É por isso que o Brasil

${ }^{21}$ GUIMARÃES, Bérgson Cardoso. Fundamentos ético-filosóficos para a preservação dos bens culturais. p. 101.

22 MEDEIROS, Fernanda Luiza Fontoura de; PETTERLE, Selma Rodrigues. Biodiversidade: uso inclusivo e sustentável do ambiente. In: Revista Magister de Direito Ambiental e Urbanístico. Porto Alegre: Magister, 2005, p. 34. 
BASTIANI, Ana Cristina Bacega de; SANTOS, Daniela dos. A condição humana e o respeito à dignidade na proteção do direito ao meio ambiente saudável previsto pelo artigo 225 da Constituição Federal. Revista Eletrônica Direito e Política, Programa de Pós-Graduação Stricto Sensu em Ciência Jurídica da UNIVALI, Itajaí, v.10, n.1, edição especial de 2015. Disponível em: www.univali.br/direitoepolitica - ISSN 1980-7791.

protege em sua Lei Maior, condições para que este modelo possa se concretizar. A Constituição prevê direitos fundamentais, sendo a dignidade da pessoa humana como um de seus fundamentos, e, dentre o amplo catálogo de direitos protegidos, está o direito a um meio ambiente saudável para a essencial qualidade de vida de seus integrantes.

Isso implica dizer, que os homens, tem amplamente direitos protegidos, mas também implica que como ser participativo do modelo de Estado que está inserido, o homem também tem o dever de preservar estas condições para que a dignidade humana possa continuar a ser respeitada perante as futuras gerações. A qualidade de vida prevista pelo artigo 225 da Carta Magna está intimamente ligada ao respeito da dignidade humana, a partir da preservação de um meio ambiente equilibrado. Aqui, fica evidente a importância das ações sustentáveis para a preservação do meio.

Germano Schwartz ${ }^{23}$ explica que

O artigo $1^{\circ}$ da Constituição de 1988 estabelece o Brasil como um Estado Democrático de Direito, o que implica algumas características/princípios vinculantes ao modelo estatal que se quer implantar, todas elas ligadas a uma reestruturação/transformação da sociedade. É um vínculo jurídico-ético-político do qual o Brasil não pode se desapegar.

E por ser um Estado Democrático de Direito que se funda em valores e princípios relevantes para uma sociedade livre, tendo sempre como objetivo a busca por justiça social, no que concerne o direito a um meio ambiente equilibrado, "vale dizer que o Estado Democrático de Direito impõe a todos os componentes da sociedade brasileira o dever de se buscar a transformação da realidade" ${ }^{24}$.

Existe o dever de tutelar a preservação do meio ambiente saudável para que ele possa continuar sendo um recurso importante para continuação da vida humana

\footnotetext{
${ }^{23}$ SCHWARTZ, Germano André Doederlein. Direito a saúde: efetivação em uma perspectiva sistêmica. Porto Alegre: Livraria do Advogado, 2001. p.49.

${ }^{24}$ SCHWARTZ, Germano André Doederlein. Direito a saúde: efetivação em uma perspectiva sistêmica. p. 50.
} 
BASTIANI, Ana Cristina Bacega de; SANTOS, Daniela dos. A condição humana e o respeito à dignidade na proteção do direito ao meio ambiente saudável previsto pelo artigo 225 da Constituição Federal. Revista Eletrônica Direito e Política, Programa de Pós-Graduação Stricto Sensu em Ciência Jurídica da UNIVALI, Itajaí, v.10, n.1, edição especial de 2015. Disponível em: www.univali.br/direitoepolitica - ISSN 1980-7791.

com dignidade, que caracteriza a condição humana. Segundo Schwartz ${ }^{25}$, "resta evidente que o Estado Democrático de Direito supera o império da lei, típico do Estado de Direito". O que ocorre é que a proteção deste direito a um meio ambiente equilibrado, essencial à sadia qualidade de vida do homem depende, muitas vezes, da consciência do homem de que ele é o ser condicionante desta preservação e também da vontade e atitude de implantar políticas para esta preservação. Quando isso acontece começam a aparecer os problemas inerentes ao tema tratado.

Schwartz ${ }^{26}$ observa que a concretização de um direito tão importante, do qual muitos outros direitos decorrem e implicam proteção, implica várias consequências inimagináveis e não pode estar condicionada a

[...] discursos vagos, promessas políticas e ideologias cambaleantes. A condição primordial para o desenvolvimento de qualquer regime democrático é a vida do ser humano, que não pode ser colocada em segundo plano por distorções ideológicas que têm como grande objetivo disfarçar os reais e egoísticos interesses implícitos em ditas falas.

É importante esclarecer que o Estado deve prever na sua Lei Maior a proteção a um meio ambiente saudável, essencial à vida humana e promover mecanismos para a efetiva proteção. Porém, a relevância da consciência humana e ações conscientes para preservar o meio são fundamentais para que a preservação do meio seja uma realidade. Preservar o meio ambiente, do qual o próprio homem depende trata-se de uma responsabilidade social comum a todos.

Explicam Medeiros e Petterle 27 , que "o ser humano, ao mesmo tempo em que necessita explorar os recursos naturais, é também completamente dependente deles, o que o torna imprescindível para uma boa vida, para uma vida digna".

${ }^{25}$ SCHWARTZ, Germano André Doederlein. GLOECKNER, Ricardo Jacobsen. Gestão Compartida sanitária no Brasil possibilidade de efetivação do direito à saúde. In: SCHWARTZ, Germano (Org.). A saúde sob os cuidados do direito. Passo Fundo: UPF, 2003, p. 123.

26 SCHWARTZ, Germano André Doederlein. Direito a saúde: efetivação em uma perspectiva sistêmica. p. 161.

27 MEDEIROS, Fernanda Luiza Fontoura de; PETTERLE, Selma Rodrigues. Biodiversidade: uso inclusivo e sustentável do ambiente.p.34. 
BASTIANI, Ana Cristina Bacega de; SANTOS, Daniela dos. A condição humana e o respeito à dignidade na proteção do direito ao meio ambiente saudável previsto pelo artigo 225 da Constituição Federal. Revista Eletrônica Direito e Política, Programa de Pós-Graduação Stricto Sensu em Ciência Jurídica da UNIVALI, Itajaí, v.10, n.1, edição especial de 2015. Disponível em: www.univali.br/direitoepolitica - ISSN 1980-7791.

Impõe-se então, uma limitação ao comportamento do agir humano, não basta somente neste caso exigir do Estado que ele tome as providências necessárias para a efetivação deste direito. O homem é o responsável direto pela degradação ou preservação do meio em que vive e depende dele para sobreviver.

Como bem advertiu Schwartz ${ }^{28}$, é preciso que o cidadão tenha a consciência de seus deveres e busque seus direitos, pois um dos "princípios do Estado democrático de direito é a busca da justiça social" (grifo do autor). Desta forma, tem o Estado o dever de implantar condições de efetivar este direito fundamental. Contudo, o homem não pode ficar passivo, já que como agente transformador da sociedade, tem um papel neste mundo e precisa exercê-lo com a devida consciência.

É por meio das ações humanas que o processo de evolução se desenvolve, fomentando um sentimento de "solidariedade, de sobrevivência conjunta". ${ }^{29}$

Percebe-se que a busca desenfreada pelo progresso tem desvirtuado as ações humanas e isso tem gerado graves consequências, que podem afetar profundamente a vida humana e enfraquecer o próprio regime democrático. 0 progresso é uma de suas vertentes, todavia, não a única. Como se sabe, o importante é o equilíbrio entre as condições ${ }^{30}$.

Neste caso, o homem é o responsável por atuar na mudança das ações para que referida busca pela evolução possa respeitar suas condições de homem não afetando os recursos que ele próprio depende para sua existência. Jonas ${ }^{31}$ esclarece que "se o dever em relação ao homem se apresenta como prioritário,

${ }^{28}$ SCHWARTZ, Germano André Doederlein. GLOECKNER, Ricardo Jacobsen. Gestão Compartida sanitária no Brasil possibilidade de efetivação do direito à saúde. p. 122.

${ }^{29}$ GUIMARÃES, Bérgson Cardoso. Fundamentos ético-filosóficos para a preservação dos bens culturais. p. 98 .

30 "Os perigos inerentes à própria ideia democrática surgem quando um dos ingredientes dela é isolado e absolutizado. O que reúne esses diversos perigos é a presença de uma forma de descomedimento. O povo, a liberdade, o progresso são elementos constitutivos da democracia; mas se um deles se emancipa de suas relações com os outros, escapando assim a qualquer tentativa de limitação e erigindo-se em único e absoluto, eles transformam-se em ameaças." (TODOROV, 2012, p. 18)

31 JONAS, Hans. O princípio da responsabilidade: ensaio de uma ética para a civilização tecnológica. Trad. Marijane Lisboa; Luiz Barros Montez. Rio de Janeiro: Contraponto: Ed. PUC Rio, 2006. p. 230. 
BASTIANI, Ana Cristina Bacega de; SANTOS, Daniela dos. A condição humana e o respeito à dignidade na proteção do direito ao meio ambiente saudável previsto pelo artigo 225 da Constituição Federal. Revista Eletrônica Direito e Política, Programa de Pós-Graduação Stricto Sensu em Ciência Jurídica da UNIVALI, Itajaí, v.10, n.1, edição especial de 2015. Disponível em: www.univali.br/direitoepolitica - ISSN 1980-7791.

ele deve incluir o dever em relação à natureza, como condição de sua própria continuidade e como um dos elementos da sua própria integridade existência".

Para Moraes ${ }^{32}$, a preservação do meio ambiente juntamente a promoção da qualidade de vida pode ser vista como um

Direito subjetivo, mas como a concretização de um princípio a ser referendado pela atuação jurídico-política do Estado [...] Isso requer que o conjunto das relações sociais se dê com vistas ao reordenamento da qualidade do cotidiano das pessoas, a sua adequação ao objetivo de promover - dar impulso, trabalhar a favor, favorecer 0 progresso, fazer avançar, fomentar - a vida (grifo do autor).

Figueiredo $^{33}$ nesse sentido acrescenta que a vida digna é equiparada a uma vida saudável. A autora aproxima os conceitos de qualidade de vida e dignidade da pessoa humana, entendendo que o completo bem-estar corrobora o princípio da dignidade humana, pois é inimaginável que condições de vida insalubres em um ambiente inadequado sejam aceitas como conteúdo de uma vida com dignidade.

A condição humana serve como uma máxima à dignidade humana e para seu respeito, o homem deve viver em condições ambientais equilibradas e adequadas. A conquista da positivação e exigência de tutela desses direitos nada mais é do que fruto das próprias lutas e do conhecimento humano, fazendo com que o homem se modifique e também transforme o mundo, preservando e melhorando o ambiente ao seu redor para conquistar uma melhor qualidade de vida e, assim, a efetivação de seus direitos.

O direito fundamental a um meio ambiente equilibrado, a partir de ações humanas sustentáveis ainda é um direito em constante construção. Como há a previsão constitucional, é preciso continuar desenvolvendo e justificando este direito sob este aspecto, visto que se ratificado nesta perspectiva, protegerá intimamente a condição humana e a dignidade. Como esta é um dos fundamentos deste Estado Democrático de direito, é necessário promover uma

\footnotetext{
32 MORAES, Luis Bolzan de. O direito da saúde. In: SCHWARTZ, Germano (Org.). A saúde sob os cuidados do direito. Passo Fundo: UPF, 2003, p.24.

${ }^{33}$ FIGUEIREDO, Mariana Filchtiner. Direito fundamental à saúde: parâmetros para sua eficácia e efetividade.p.82
} 
BASTIANI, Ana Cristina Bacega de; SANTOS, Daniela dos. A condição humana e o respeito à dignidade na proteção do direito ao meio ambiente saudável previsto pelo artigo 225 da Constituição Federal. Revista Eletrônica Direito e Política, Programa de Pós-Graduação Stricto Sensu em Ciência Jurídica da UNIVALI, Itajaí, v.10, n.1, edição especial de 2015. Disponível em: www.univali.br/direitoepolitica - ISSN 1980-7791.

consciência humana sustentável, pois a busca de uma qualidade de vida humana depende de suas próprias ações para acontecer. Para que uma qualidade de vida ocorra, muitos direitos fundamentais devem ser ratificados, proporcionando ao homem uma vida e um estado de bem-estar. Medeiros e Petterle ${ }^{34}$ falam até mesmo em uma "qualidade e sustentabilidade de vida".

Portanto, a redefinição de alguns conceitos e direitos importa na base para a construção de um direito à sustentabilidade, a partir do artigo 225 da Constituição Federal brasileira. Parte-se da ideia da defesa dos direitos pelo Estado e das ações do homem como agente transformador da sociedade, responsável pelas consequências geradas por suas ações perante o meio ambiente. É neste sentido então, que Medeiros e Petterle ${ }^{35}$ esclarecem a importância de

[...] uma ação de inclusão vinculada à tematização de uma ética ambiental que faz retomar dimensões para tratarmos o meio ambiente também como um dever fundamental, correspondendo a uma liberdade acompanhada da devida responsabilidade social do indivíduo. (grifo do autor).

A proteção a um meio ambiente equilibrado a partir de ações sustentáveis é o caminho para que o homem possa continuar progredindo. Não é possível continuar desrespeitando os recursos naturais, dos quais o próprio homem necessita para sobreviver.

Quando se refere à qualidade de vida, preconizado pelo artigo 225 da Constituição Federal, está-se diante de um plus às condições de vida existenciais. Contudo, não é possível considerar a qualidade de vida se as condições ambientais não forem efetivamente respeitadas. Sem um meio ambiente equilibrado e adequado, futuramente não se garante nem mesmo existência humana. Por isso ressalta-se a importância da consciência humana a respeito do quanto suas ações influenciam para este processo de desenvolvimento.

\footnotetext{
${ }^{34}$ MEDEIROS, Fernanda Luiza Fontoura de; PETTERLE, Selma Rodrigues. Biodiversidade: uso inclusivo e sustentável do ambiente. p. 6.

35 MEDEIROS, Fernanda Luiza Fontoura de; PETTERLE, Selma Rodrigues. Biodiversidade: uso inclusivo e sustentável do ambiente. p. 6.
} 
BASTIANI, Ana Cristina Bacega de; SANTOS, Daniela dos. A condição humana e o respeito à dignidade na proteção do direito ao meio ambiente saudável previsto pelo artigo 225 da Constituição Federal. Revista Eletrônica Direito e Política, Programa de Pós-Graduação Stricto Sensu em Ciência Jurídica da UNIVALI, Itajaí, v.10, n.1, edição especial de 2015. Disponível em: www.univali.br/direitoepolitica - ISSN 1980-7791.

\section{CONSIDERAÇÕES FINAIS}

O Estado Brasileiro hoje é um dos mais avançados no tocante à proteção e respeito aos direitos de seus cidadãos. Ao longo dos tempos, houve avanços gradativos jurídicos e políticos nessa proteção, e o país encontra-se em um momento importante no que se refere à previsão constitucional dos direitos fundamentais. A busca pela confirmação dos direitos ainda ocorre e a cada dia de maneira mais intensa. Para essa ratificação, é necessário que esses direitos sejam tratados com a seriedade que merecem.

O Estado deve proporcionar aos seus cidadãos, além da certeza de proteção jurídica de seus direitos, a percepção real de tais direitos. Não se deve esquecer o dever humano de atuar de maneira sustentável para que seus direitos possam ser exercidos: são as ações humanas cotidianas que transformam as condições ambientais.

Desse modo, é relevante a participação humana no processo de desenvolvimento. Em um Estado Democrático de Direito, é preciso promover políticas de desenvolvimento econômico sustentável, e cabe ao homem - agente da transformação - conscientizar-se de que suas ações individuais fazem toda a diferença na preservação do meio em que vive. Cada ser humano exerce um papel quando se refere à Sustentabilidade. Proteger o meio ambiente e as suas condições, resulta na realização da dignidade da pessoa humana, possibilitando qualidade de vida e manutenção de um Estado Democrático; onde todos participam do processo de desenvolvimento exercendo seu papel de cidadão, livre e igual, mas consciente de seu papel de responsabilidade participativa.

O homem, atendendo à condição humana, segue o caminho da evolução. Se a condição humana é um valor base para o princípio da dignidade, e esta se satisfaz quando a qualidade de vida acontece certo é que a condição humana também é observada quando da proteção da qualidade de vida, porque demonstra na prática o progresso humano. A continuidade deste progresso depende da conscientização e das ações humanas. 
BASTIANI, Ana Cristina Bacega de; SANTOS, Daniela dos. A condição humana e o respeito à dignidade na proteção do direito ao meio ambiente saudável previsto pelo artigo 225 da Constituição Federal. Revista Eletrônica Direito e Política, Programa de Pós-Graduação Stricto Sensu em Ciência Jurídica da UNIVALI, Itajaí, v.10, n.1, edição especial de 2015. Disponível em: www.univali.br/direitoepolitica - ISSN 1980-7791.

No que toca ao direito a Sustentabilidade, conclui-se que Estado Democrático de Direito exige a participação popular no processo de construção deste Estado, e por tal, todos os homens devem colaborar. Assim, demonstra-se a relevância do que foi aqui tratado. O direito à sustentabilidade é um novo paradigma e demonstra sua importância na medida em que será um possibilitador da ratificação de muitos outros direitos fundamentais.

A condição humana serviu como base para o estudo, pois ela evidencia o processo civilizatório. Ao ter melhores condições de vida, o princípio da dignidade humana, fundamento da Constituição Federal, se realiza. A proteção ao direito a um meio ambiente equilibrado, essencial à sadia qualidade de vida, unifica toda a pesquisa, já que o homem depende de boas condições ambientais para sua sobrevivência e seu bem estar. Do homem depende a realização da qualidade de vida, a partir de condições ambientais equilibradas e adequadas, que realizem a dignidade humana e possibilitem condições de evolução do qual a condição humana se refere.

\section{REFERÊNCIAS DAS FONTES CITADAS}

ARENDT, Hannah. A condição humana. Trad. Roberto Raposo. 10. ed. Rio de Janeiro: Forense Universitária, 2007.

BRASIL. Constituição, 1988. Constituição da República Federativa do Brasil, de 05 de outubro de 1988. 3. ed. São Paulo: Atlas, 2009.

BOBBIO, Norberto. A Era dos Direitos. Trad. Carlos Nelson Coutinho. 6. ed. Rio de Janeiro: Elsevier, 2004.

COMPARATO, Fábio Konder. Sobre a legitimidade das constituições. In: BONAVIDES, Paulo; LIMA, Francisco Gérson Marques de; BEDÊ, Faya Silveira (Orgs.). Constituição e Democracia: estudos em homenagem ao Professor J. J. Canotilho. São Paulo: Malheiros Editores, 2006, p. 49-88.

DIMOULIS, Dimitri; MARTINS, Leonardo. Teoria geral dos direitos fundamentais. São Paulo: Editora Revista dos Tribunais, 2007.

FIGUEIREDO, Mariana Filchtiner. Direito fundamental à saúde: parâmetros para sua eficácia e efetividade. Porto Alegre: Livraria do Advogado Editora, 2007. 
BASTIANI, Ana Cristina Bacega de; SANTOS, Daniela dos. A condição humana e o respeito à dignidade na proteção do direito ao meio ambiente saudável previsto pelo artigo 225 da Constituição Federal. Revista Eletrônica Direito e Política, Programa de Pós-Graduação Stricto Sensu em Ciência Jurídica da UNIVALI, Itajaí, v.10, n.1, edição especial de 2015. Disponível em: www.univali.br/direitoepolitica - ISSN 1980-7791.

GUIMARÃES, Bérgson Cardoso. Fundamentos ético-filosóficos para a preservação dos bens culturais. In: Revista Magister de Direito Ambiental e Urbanístico. Porto Alegre: Magister, 2013, p. 93-109.

JONAS, Hans. O princípio da responsabilidade: ensaio de uma ética para a civilização tecnológica. Trad. Marijane Lisboa; Luiz Barros Montez. Rio de Janeiro: Contraponto: Ed. PUC - Rio, 2006.

KANT, Immanuel. Fundamentação da metafísica dos costumes. Trad. Paulo Quintela. Lisboa: Edições 70, 1995.

MORAES, Luis Bolzan de. O direito da saúde. In: SCHWARTZ, Germano (Org.). A saúde sob os cuidados do direito. Passo Fundo: UPF, 2003, p.11-26.

MEDEIROS, Fernanda Luiza Fontoura de; PETTERLE, Selma Rodrigues. Biodiversidade: uso inclusivo e sustentável do ambiente. In: Revista Magister de Direito Ambiental e Urbanístico. Porto Alegre: Magister, 2005, p. 5-35.

PIOVESAN, Flávia. Temas de direitos humanos. São Paulo: Max Limonad, 2003.

REIS, Jorge Renato dos. Os direitos fundamentais de tutela da pessoa humana nas relações entre particulares. In: REIS, Jorge Renato dos; LEAL, Rogério Gesta (Org). Direitos sociais \& políticas públicas: desafios contemporâneos. Santa Cruz do Sul: EDUNISC, 2007, p. 2033-2064.

SARLET, Ingo Wolfgang. Dignidade da pessoa humana e direitos fundamentais na Constituição Federal de 1988. 5. ed. Porto Alegre: Livraria do Advogado Ed., 2007.

A eficácia dos direitos fundamentais: uma teoria geral dos direitos fundamentais na perspectiva constitucional. 10. ed. Porto Alegre: Livraria do Advogado, 2009.

SCHWARTZ, Germano André Doederlein. Direito a saúde: efetivação em uma perspectiva sistêmica. Porto Alegre: Livraria do Advogado, 2001.

; GLOECKNER, Ricardo Jacobsen. Gestão Compartida sanitária no Brasil possibilidade de efetivação do direito à saúde. In: SCHWARTZ, Germano (Org.). A saúde sob os cuidados do direito. Passo Fundo: UPF, 2003, p. 108-162.

STEINMETZ, Wilson Antonio. Colisão de direitos fundamentais e princípio da proporcionalidade. Porto Alegre: Livraria do Advogado, 2001.

TODOROV, Tzvetan, Os inimigos íntimos da democracia. Tradução de Joana Angélica d'Avila Melo. São Paulo: Companhia das Letras, 2012.

Submetido em: Setembro/2014

Aprovado em: Outubro/2014 